\title{
Triggering Dissymmetry in Achiral Dye Molecules by Chiral Solvents: Circular Dichroism Experiments and DFT Calculations
}

\author{
SERGIO ABBATE, ${ }^{1,2 *}$ FRANCE LEBON ${ }^{1,2}$ GIOVANNA LONGHI ${ }^{1,2}$ MARCO PASSARELLO ${ }^{1,3}$ AND VINCENZO TURCO LIVERI ${ }^{3}$ \\ ${ }^{1}$ Dipartimento di Scienze Biomediche e Biotecnologie, Università di Brescia, Viale Europa 11, 25123 Brescia, Italy \\ ${ }^{2}$ CNISM, Consorzio Interuniversitario Scienze Fisiche della Materia, Via della Vasca Navale 84, 00146 Roma, Italy \\ ${ }^{3}$ Dipartimento di Chimica "S. Cannizzaro," Università degli Studi di Palermo, Viale delle Scienze Parco d’Orleans II, \\ 90128 Palermo, Italy
}

\begin{abstract}
The electronic circular dichroism spectra of achiral product "Lumogen $\mathrm{F}$ Red" (ROT-300) in four different chiral solvents are recorded at different temperatures. DFT calculations allow to identify two enantiomeric conformers for ROT-300. In vacuo they are equally populated; in chiral solvents one enantiomer prevails. Thermodynamic quantities involved in the chiral preference are derived. Chirality 23:910-915, 2011. @ 2011 Wiley-Liss, Inc.
\end{abstract}

KEY WORDS: circular dichroism (CD); time-dependent density functional theory (TDDFT); dye molecules, solvent effect

\section{INTRODUCTION}

The solvent dependence of chiroptical spectra has been the theme of several studies; data have been reported for optical rotation or optical rotatory dispersion, ${ }^{1-3}$ for electronic circular dichroism $(\mathrm{ECD})^{4-7}$ and for vibrational circular dichroism (VCD) ${ }^{8,9}$ In the cited ECD and VCD cases two effects were monitored: the change of intensity of ECD and VCD signals and/or the shift of the center-band frequencies of ECD or VCD bands of chiral molecules by different solvents, due to solvent polarity; sometimes the induction of some asymmetry by the solute chiral molecules onto achiral solvents was observed and explained. ${ }^{9,10}$ Here we report on a case, where an achiral compound, whose commercial name is Lumogen $\operatorname{Red} 300$, i.e., $N, N^{\prime}$-bis(2,6-diisopropylphenyl)1,6,7,12-tetraphenoxyperylene-3,4:9,10-tetracarboxydiimide (see Scheme 1) is dissolved in several chiral solvents. ROT300 is a dye molecule that is under investigation for possible use as a laser-active substance. ${ }^{11}$ It consists of a central perylene $\pi$-conjugated system with four O-phenyl pendant groups and two terminal conjugated systems bonded through $\mathrm{N}$ atoms to the central moiety. A previous investigation ${ }^{12}$ exists based on HPLC, NMR, and CD on similar molecules, whose enantiomers had been separated and studied in achiral solvents.

\section{EXPERIMENTAL AND CALCULATIONS}

ROT-300 has been obtained from Kremer Pigmente which sells the product synthetized in the BASF laboratory in Germany.

ROT-300 was dissolved in several chiral solvents, namely (-)-diethyl D-tartrate and (+)-diethyl L-tartrate; $(R)-(+)$-methyl lactate and $(S)-(-)$ methyl lactate; $(R)-(-)$-carvone and $(S)-(+)$-carvone, and $(R)-(+)$-phenylethanol and (S)-(-)-phenylethanol at $2.2 \times 10^{-4} \mathrm{M}$ concentration.

ECD and UV absorption spectra were taken simultaneously on a Jasco 815-SE spectropolarimeter in a thermostated $1 \mathrm{~mm}$ quartz cylindrical cell (for the phenylethanol solutions in the $280-400 \mathrm{~nm}$ range we used a 2.2 $\times 10^{-3} \mathrm{M}$ solution in $0.1 \mathrm{~mm}$ cell), averaging over 10 scans $(\tau=2 \mathrm{~s}$, scanning speed $=100 \mathrm{~nm} / \mathrm{min}$, spectral bandwidth $=1 \mathrm{~nm}$ ) and spectra were solvent substracted. Other concentrations were tested by ECD at room temperature for the diethyl tartrate solvents, ranging from $2.2 \times$ $10^{-5} \mathrm{M}$ to $10^{-3} \mathrm{M}$ (and for UV spectra from $2.2 \times 10^{-6} \mathrm{M}$ ).

The geometry optimization of a single ROT-300 molecule in vacuo was calculated with Gaussian $09^{13}$ using the B3LYP functional and the 6-

(C) 2011 Wiley-Liss, Inc.
$31 \mathrm{G}^{\star}$ basis set. ECD spectra were calculated using time-dependent DFT calculations (TD-DFT) ${ }^{14}$ at the same functional and basis set level considering 14 excited states.

$\varepsilon$ and $\Delta \varepsilon$ have been evaluated from the calculated dipole and rotational strengths and a width of $0.14 \mathrm{eV}$ applied to Lorentzian bands gives a good fitting with the experimental data.

\section{RESULTS AND DISCUSSION}

Solutions of ROT-300 in four enantiomeric couples of the chiral solvents $(-)$-diethyl D-tartrate and $(+)$-diethyl L-tartrate; $(R)-(+)$-methyl lactate and $(S)-(-)$-methyl lactate; $(R)$ $(-)$-carvone and $(S)-(+)$-carvone, and $(R)-(+)$-phenylethanol and $(S)-(-)$-phenylethanol) were prepared. Some other commercial chiral solvents were tried but we did not get positive results, mainly due to low solubility. ECD and UV absorption spectra were taken simultaneously to properly evaluate the dissymmetry $\mathrm{g}$ factor and were presented in Figure 1 (panels a-d).

In Figure 1 one may observe that enantiomeric solvents produce enantiomeric ECD spectra in the region where just ROT-300 absorbs. All spectra look similar in shape, though with different $\Delta \mathrm{A}$, meaning to us that the ROT molecule is subject to the same phenomena in different chiral solvents, but to different extent. The observed mirror-image appearance of ECD spectra in enantiomeric solvents guarantees that the data are reliable; the $\Delta A$ values observed are for concentrations ranging from $10^{-4}$ to $10^{-3} \mathrm{M}$, but concentration times pathlength is equal in all cases and thus the $\Delta A$ values are directly comparable.

For completeness, in panel e of Figure 1 we report the UV spectra of ROT-300 in the four solvents (of course in this case the UV data relative to only one enantiomeric species is needed).

\footnotetext{
Additional Supporting Information may be found in the online version of this article.

Contract grant sponsor: Italian "Ministero dell'Istruzione, dell'Università e della Ricerca” (MIUR); Contract grant numbers: PRIN 2008LYSEBR.

*Correspondence to: Sergio Abbate, Dipartimento di Scienze Biomediche e Biotecnologie, Università di Brescia, Viale Europa 11, 25123 Brescia, Italy. E-mail: abbate@med.unibs.it

Received for publication 18 April 2011; Accepted 21 June 2011 DOI: $10.1002 /$ chir.21012

Published online 26 September 2011 in Wiley Online Library

(wileyonlinelibrary.com).
} 


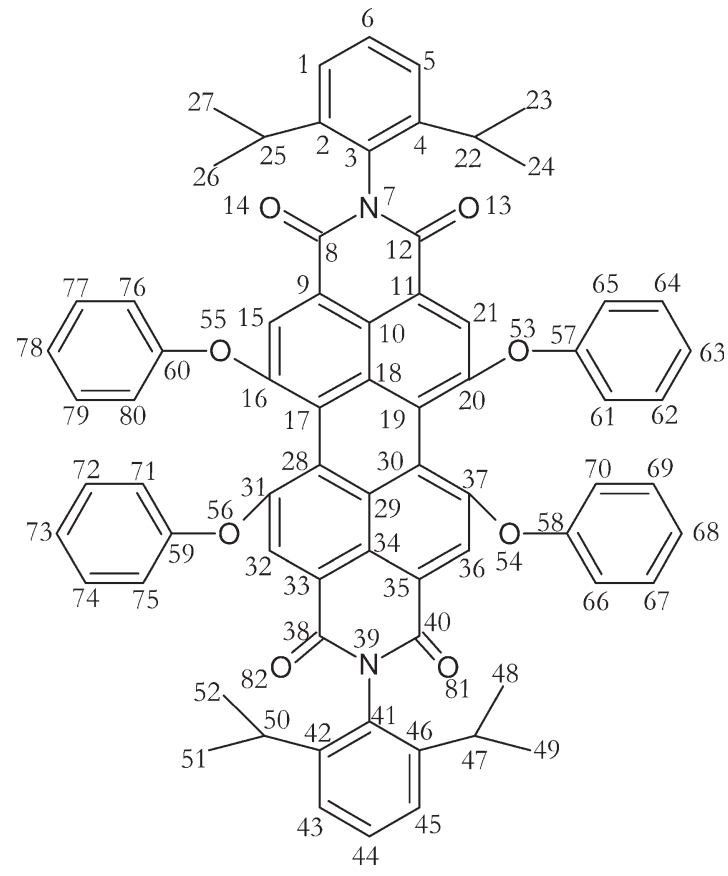

Scheme 1. Molecular formula of ROT-300 with atom numbering established by the Chemistry software tool employed by us.
All ECD spectra are similar and present a broad structured asymmetric feature at about $580 \mathrm{~nm}$. In the different solvents the region between $480 \mathrm{~nm}$ and $350 \mathrm{~nm}$ shows bands of opposite sign and smaller intensity. Finally at about $300 \mathrm{~nm}$ one observes, except for the carvone solution, which is not transparent in that range, a narrow and fairly intense ECD band with the same sign as the $580 \mathrm{~nm}$ broad ECD band.

The observed ECD bands correspond to the observed UV absorption bands. Due to better signal to noise ratio of UV data with respect to ECD data, one may safely assume that in phenylethanol there is a definite red-shift of the UV band to $585 \mathrm{~nm}$ with respect to the other solvents. The same effect may be observed on the ECD band at about $580 \mathrm{~nm}$, even though the data are noisier, being less intense.

In Supporting Information (Figs. S1-S3), we report CD, absorption and fluorescence spectra of ROT-300 in diethyl-Dtartrate and diethyl--tartrate at different concentration values to show that the observed $\mathrm{CD}$ signals can be assumed as due to the isolated ROT-300 molecule; aggregation has minimal influence.

A clue for understanding why enantiomeric ECD spectra of ROT-300 compounds are generated when enantiomeric solvents are used is found by performing DFT calculations. The optimized structure obtained with the programs' pack-
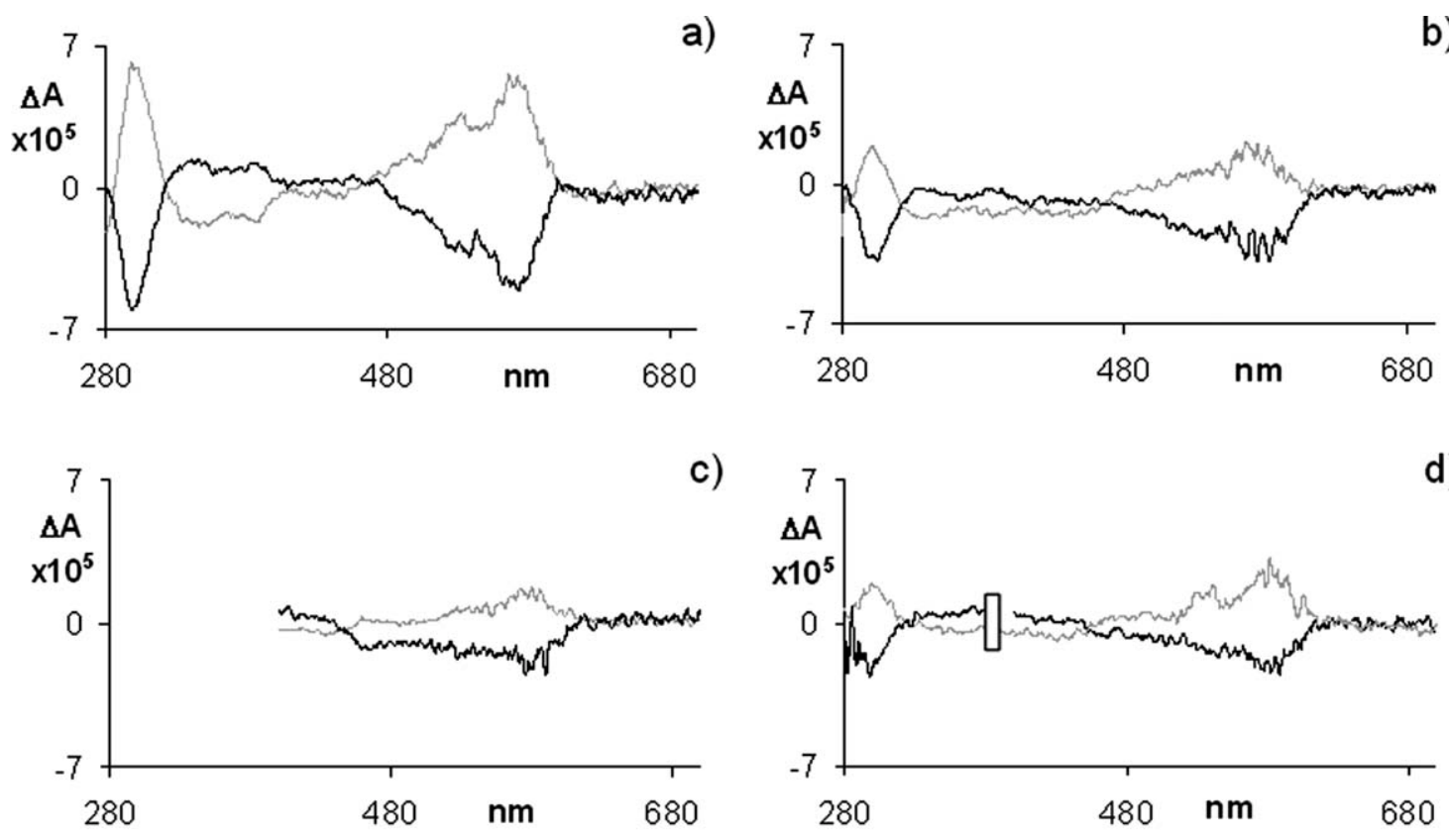

c)
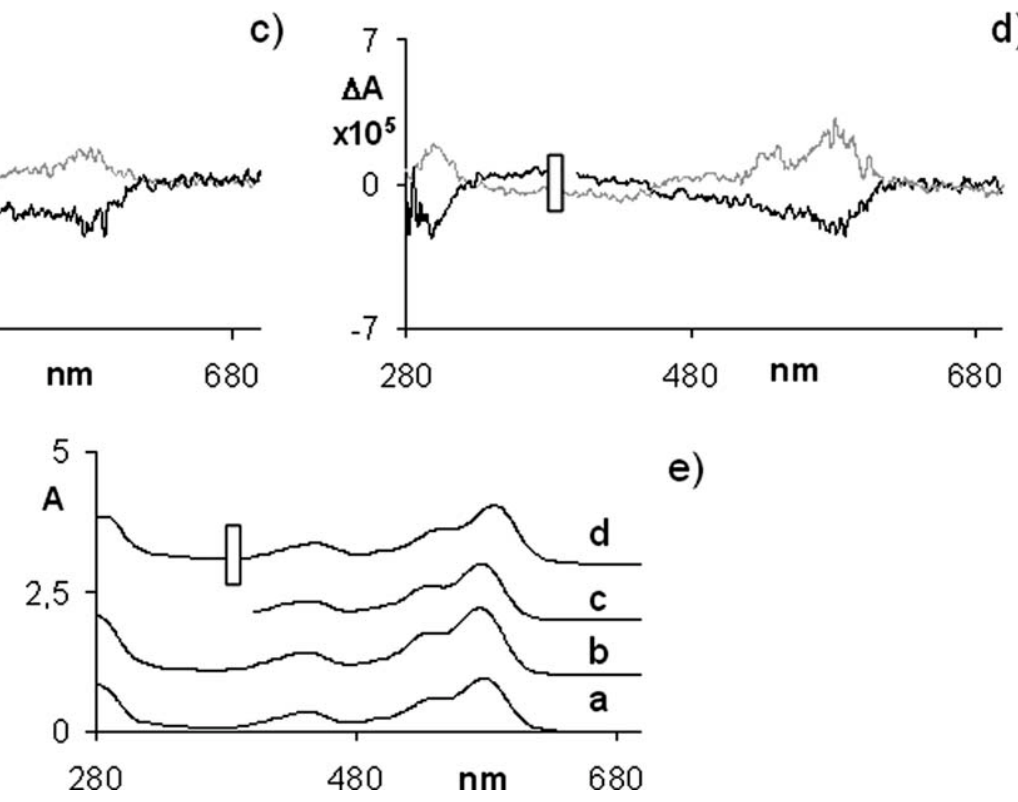

e)

Fig. 1. ECD spectra of ROT-300 in: (a) (+)-diethyl L-tartrate (gray) and (-)-diethyl D-tartrate (black) (DLT and DDT, respectively); (b) $(R)-(+)$-methyl-lactate (gray) and $(S)-(-)$-methyl-lactate (black); (c) $(R)$ - $(-)$-carvone (gray) and $(S)-(+)$-carvone (black); $(\mathbf{d})(R)$ - $(+)$-phenylethanol (gray); and $(S)-(-)$-phenylethanol (black); (e) UV of ROT-300 in DLT (a), $S(-)$ ML (b), $(R)-(-)$-carvone (c) and (S)-(-)-phenylethanol (d). For phenylethanol, the UV and ECD spectra between 280 and $400 \mathrm{~nm}$ were obtained with the $0.1 \mathrm{~mm}$ cell; $2.2 \times 10^{-3} \mathrm{M}$. 

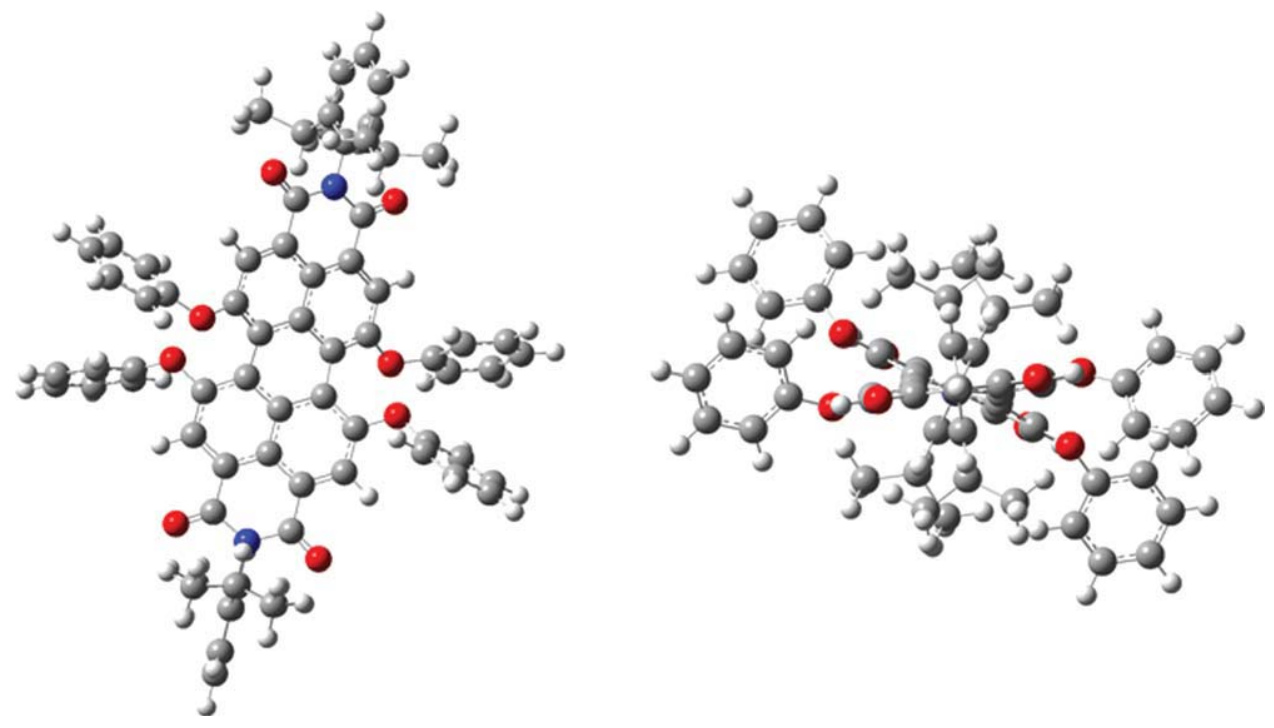

Fig. 2. Two different views of an optimized minimum energy geometry of ROT-300 in vacuo obtained by DFT calculation as described in the text. [Color figure can be viewed in the online issue, which is available at wileyonlinelibrary.com.]

age Gaussian $09^{13}$ is presented in Figure 2. An overall dissymmetric structure is indeed observed even by mere inspection of Figure 2; it consists in the distorted central perylene unit, reminding the form of a twisted ribbon, in the asymmetric arrangement of the four O-phenyl groups in the periphery of the central perylene moiety, in the dihedral angle formed by the two planes containing the terminal $N$ phenyl-isopropyl groups being different from zero and finally in the four isopropyl groups attached to the two terminal $\mathrm{N}$ phenyl groups being twisted. The structure of Figure 2 may be defined of $P$-type, according to the accepted nomenclature. ${ }^{15}$ Of course the opposite $M$-type structure, has equal energy as the $P$ one, while the flat achiral structure has higher energy and is not a minimum. In Table 1 we report the values for the relevant dihedral angles of ROT-300, allowing us to quantitatively measure the distortion from planarity. From Table 1 we conclude that an overall distortion of the molecular backbone of about $30^{\circ}$ is predicted on the basis of DFT calculations, as measured by the dihedral angle 15-21$36-32\left(c a, 32^{\circ}\right)$. This distorted dihedral angle has a value equal to those observed for the two sides of the perylene, on the left (16-17-28-31) and on the right (20-19-30-37) in Figure 2 . The distorsion involves also the relative angle between the two terminal $N$-phenyl-isopropyl groups (1-5-45-43) and the relative dihedrals of the isopropyls at one terminal with respect to the isopropyls at the other one (22-4-46-47 and 252-42-50). On top of that overall distortion, lateral O-phenyl groups show further distortions. From a first conformational analysis, these lateral groups present angles (like 19-20-5357) with values about $\pm 160^{\circ}$ and phenyls are oriented grossly perpendicular to the $\mathrm{COC}$ plane $\left(60-90^{\circ}\right)$, without much change in energy among the different allowed orientations about the $\mathrm{CO}$. The previous study of Ref. 12 arrived at similar conclusions on other perylene-based molecules, by AM1 calculations.

The TDDFT calculated ECD spectra are not identical for different O-phenyl orientation, but the first transition at about
$570 \mathrm{~nm}$, HOMO-LUMO, involves just the central perylene part of the molecule. UV and ECD spectra derived for the chiral P-conformer of ROT-300 shown in Figure 2, are reported in Figure 3 where bars are proportional to calculated dipole and rotational strengths. The calculated spectra are superimposed to the corresponding experimental spectra. One may see that a good prediction is obtained in frequencies and intensities for the UV spectra, while in the CD case there is a good correspondence between calculated and experimental frequencies and signs only.

The observed rotational strengths, instead, are much weaker than the calculated ones: we interpret this as due to the fact that in solution one does not have only just one "enantiomeric" form, namely that of Figure 2, but also the opposite one, in unequal amounts, that is to say the enantiomeric excess $(e e)$ between the $M$ - and $P$-form is quite low. Indeed the calculations suggest that a larger amount of the $P$-conformer (shown in Fig. 2) is promoted by the L-enantiomeric form $((R, R)$ in absolute terms) of the diethyl tartrate molecules, while in the other three cases of Figure 1 the $P$ form of ROT-300 is preferred by the $R$-enantiomeric forms of

TABLE 1. Values of selected dihedral angles of the ROT-300 molecule, as calculated from DFT calculations (for the atomic numbering see Scheme 1)

\begin{tabular}{lcc}
\hline Groups & $\begin{array}{c}\text { Dihedral angles } \\
\text { definition }\end{array}$ & $\begin{array}{c}\text { Dihedral } \\
\text { angles values }\end{array}$ \\
\hline Perylene unit & $16-17-28-31$ & $31^{\circ}$ \\
& $20-19-30-37$ & $31^{\circ}$ \\
$N$-phenyl-isopropyl & $15-21-36-32$ & $32^{\circ}$ \\
$\quad$ groups & $1-5-45-43$ & $32^{\circ}$ \\
Isopropyl groups & $24-22-4-5 ;$ & $64^{\circ}$ \\
& $27-25-2-1 ;$ & $64^{\circ}$ \\
& $48-47-46-45 ; 49-47-46-41$ & $64^{\circ}$ \\
& $51-50-42-43 ; 52-50-42-41$ & $64^{\circ}$ \\
\hline
\end{tabular}



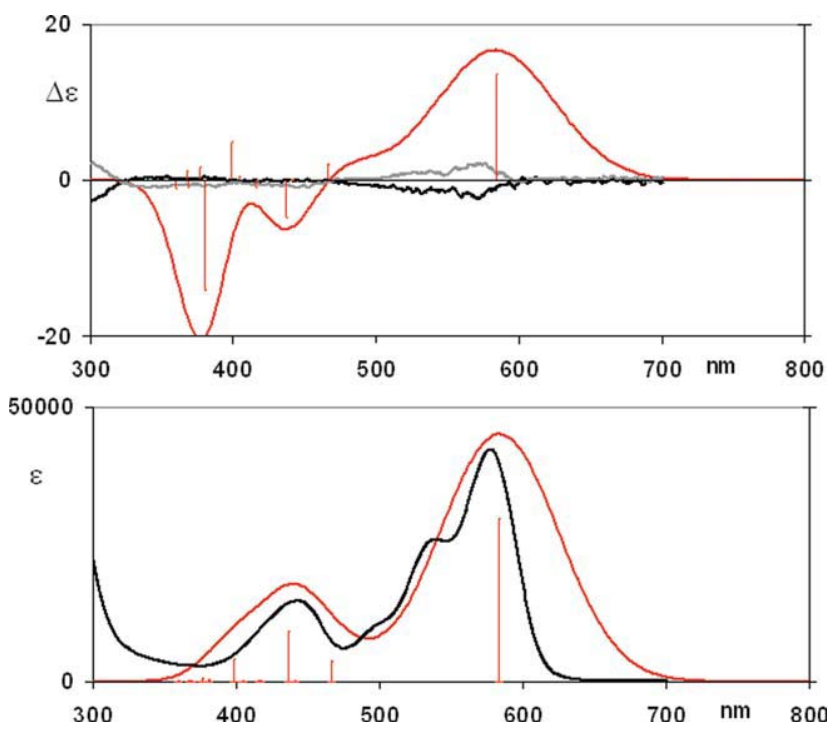

Fig. 3. Bottom: Experimental (black trace) and calculated (red trace) UV absorption spectrum of ROT-300. Top: Experimental (black and gray traces for DDT and DLT, respectively) and calculated (red trace) ECD spectrum of ROT-300. The bandwidth of $0.14 \mathrm{eV}$ is attributed to the transitions the intensity of which is reported as bars. [Here the experimental $\Delta \varepsilon$ has been determined from total concentration, namely assuming $100 \% e e$ ]. [Color figure can be viewed in the online issue, which is available at wileyonlinelibrary.com.]

the solvents. We calculate the enantiomeric excess $e e$ as follows ${ }^{16}$ : we define $e e \equiv \frac{([P]-[M])}{([P]+[M])}$ of the $P$ over the $M$ enantiomeric form, where $[P]$ and $[M]$ are the concentrations of the ROT-300 compound in a chiral solvent having a given enantiomeric form. In Figure 3 we can measure $\Delta \mathrm{A}$ and $\mathrm{A}$, which are defined as:

$$
\Delta \mathrm{A}=\left(\Delta \mathrm{A}_{\mathrm{P}}+\Delta \mathrm{A}_{\mathrm{M}}\right)=\Delta \varepsilon . l .([P]-[M])
$$

$l$ is the cell path-length; $\Delta \mathrm{A}_{\mathrm{M}}$ and $\Delta \mathrm{A}_{\mathrm{P}}$ are the differences in absorbance of left and right circularly polarized light for the $M$ - and $P$-enantiomers of ROT-300, respectively; both are related to the molecular quantity $\Delta \varepsilon=\varepsilon_{\text {Left }}-\varepsilon_{\text {Right }}$, the latter being the difference in absorption coefficients for Left and Right circularly polarized light for pure $P$ species. $\Delta \mathrm{A}$ is only due to the imbalance of enantiomeric species in solution. Similarly

$$
A=\varepsilon . l .([P]+[M])
$$

where $\varepsilon=\left(\varepsilon_{\text {Left }}+\varepsilon_{\text {Right }}\right) / 2$. Using Eqs. 1 and 2 together, we obtain:

$$
\frac{\Delta A}{A}=\frac{\Delta \varepsilon}{\varepsilon} \bullet \frac{([P]-[M])}{([P]+[M])}=\frac{\Delta \varepsilon}{\varepsilon} \bullet e e
$$

In another context, this had been previously defined in Ref. 17. We obtain $\triangle A / A$ for the most intense UV and CD experimental band area of Figure 1 (at $\approx 580 \mathrm{~nm}$ ). We may obtain $\Delta \varepsilon / \varepsilon$ for the same band in the corresponding calculated spectra of Figure 3: in this way we have $\Delta \varepsilon / \varepsilon=2.4 \times$ $10^{-4}$. The results for the $e e$ of either the $P$ over the $M$ form or viceversa due to the use of Eq. 3 to the eight cases of Figure 2 are reported in Table 2.

Abstracting from evident random errors in the measured values, we may state that the $e e$ of one ROT-300 enantiomer over the other one are about $10 \%$ for all chiral solvents, except possibly for diethyl-tartrate, where $e e$ is well above this figures. To gain further information on these systems, we took ECD and UV spectra of ROT-300 in diethyl-L-tartrate and diethyl-D-tartrate at variable temperature, in the range $253 \mathrm{~K}<T<293 \mathrm{~K}$. The results are given in Figure 4, where we superimpose the ECD spectra from both enantiomeric solvents in the top panel and the UV spectra in the bottom panel (we reiterate that the UV and ECD data were taken at the same time). One may observe that the intensities of the ECD bands increase for all features with decreasing temperature, while the UV spectra do not significantly change. This means that the $P$-ROT-300/diethyl--tartrate preference over the $M$-ROT-300/diethyl-L-tartrate increases lowering the temperature. In other words the diastereomeric $P-L$ couple prevails over the $M-L$ one to a larger extent when temperature decreases (for the opposite enantiomeric solvent, we observe an increase of the $M-D$ system over the $P-D$ one). In the absorption spectra, there were no significant observable variations in frequency or intensity, to make us conclude that the aggregation phenomena reported in the literature ${ }^{18-20}$ are negligible.

The data of Figure 4 and Table 2 permit the evaluation of thermodynamic quantities involved in the process of chiral recognition. We can define an equilibrium constant $K$ for the reaction $M \rightarrow P$ in either DLT or DDT, as $K=\frac{[P]}{[M]}=\frac{1+e e}{1-e e}$ (of course $K>1$ in DLT and $K<1$ for DDT). From the relation $\Delta G^{\circ}=-R T \ln K$, and from the data of Table 2 we have, $\Delta G^{\circ}$ $=-0.26 \mathrm{Kcal} / \mathrm{mol}$ for the DLT solvent at $T=293 \mathrm{~K}$ and $\Delta G^{\circ}=+0.21 \mathrm{Kcal} / \mathrm{mol}$ for the DDT solvent at the same temperature.

\begin{tabular}{|c|c|c|c|c|}
\hline & A & $|\Delta \mathrm{A}|$ & $|\Delta \mathrm{A} / \mathrm{A}|$ & e.e. $(\%)$ \\
\hline (-)-diethyl $D$-tartrate & $30.37(477-632 \mathrm{~nm})$ & $1.38 \times 10^{-3}(468-603 \mathrm{~nm})$ & $4.52 \times 10^{-5}$ & 19 \\
\hline$(+)$-diethyl $L$-tartrate & 38.7 & $1.42 \times 10^{-3}$ & $3.64 \times 10^{-5}$ & 15.2 \\
\hline$(S)$-(-)-methyl-lactate & $81.95(478-642 \mathrm{~nm})$ & $2.24 \times 10^{-3}$ & $2.80 \times 10^{-5}$ & 11.6 \\
\hline$(R)-(-)$-carvone & $65.89(476-628 \mathrm{~nm})$ & $7.53 \times 10^{-4}$ & $11.4 \times 10^{-6}$ & 4.8 \\
\hline$(S)$-(+)-carvone & 103.51 & $1.98 \times 10^{-3}$ & $19.2 \times 10^{-6}$ & 8.0 \\
\hline$(R)-(+)$-phenylethanol & $76.14(482-642 \mathrm{~nm})$ & $1.64 \times 10^{-3}(453-610 \mathrm{~nm})$ & $2.16 \times 10^{5}$ & 9.0 \\
\hline
\end{tabular}

TABLE 2. $|\triangle \mathrm{A} / \mathrm{A}|$ ratio and enantiomeric excess of the two enantiomeric species of ROT-300 within the chiral solvents investigated as calculated from Eq. 3 of the text $\left(\Delta \varepsilon / \varepsilon=2.4 \times 10^{-4}, T=293 \mathrm{~K}\right)$

Here the quoted $e e$ is for either the $P$ over the $M$ form or for the $M$ over the $P$ one (see text). 
In Figure 5, we plot the $\ln K$ values vs. $1 / T$ with $e e$ data derived from the ECD intensity at various $T$ of the $\sim 300 \mathrm{~nm}$ band in Figure 4 by the same method as employed in Table 2 .

From the vant'Hoff relation in the form: $\frac{d \ln K}{d\left(\frac{1}{T}\right)}=-\frac{\Delta H^{\circ}}{R}$ one has an average value for the DLT (DDT) solution: $\Delta H^{\circ}$ $=-1.28 \mathrm{Kcal} / \mathrm{mol}(+1.36 \mathrm{Kcal} / \mathrm{mol})$, and from the fundamental relation $\Delta G^{\circ}=\Delta H^{\circ}-T \Delta S^{\circ}$, one has the entropic term $\Delta S^{\circ}$, which at room temperature is $-3.5 \mathrm{cal} / \mathrm{mol} . \mathrm{K}$ $(+3.9 \mathrm{cal} / \mathrm{mol} \mathrm{K})$.

An alternative approach for deriving $\Delta G^{\circ}$ from ECD data is presented in Refs. 4 and 5, based on previous work. ${ }^{21,22}$ However in that case no entropic term was present, while here large variations of entropy $\Delta S^{\circ}$ are associated either with multiple conformers about the two enantiomers $M$ and $P$ or with different solvation mechanisms possessing the same energy. The general conclusion of the present work is that chiral solvents impair the $50 \%-50 \%$ balanced concentration of the two enantiomeric conformers for ROT-300. In vacuo the latter conformers have equal energy and free energy; in chiral solvents one enantiomeric form of the solvent favors one
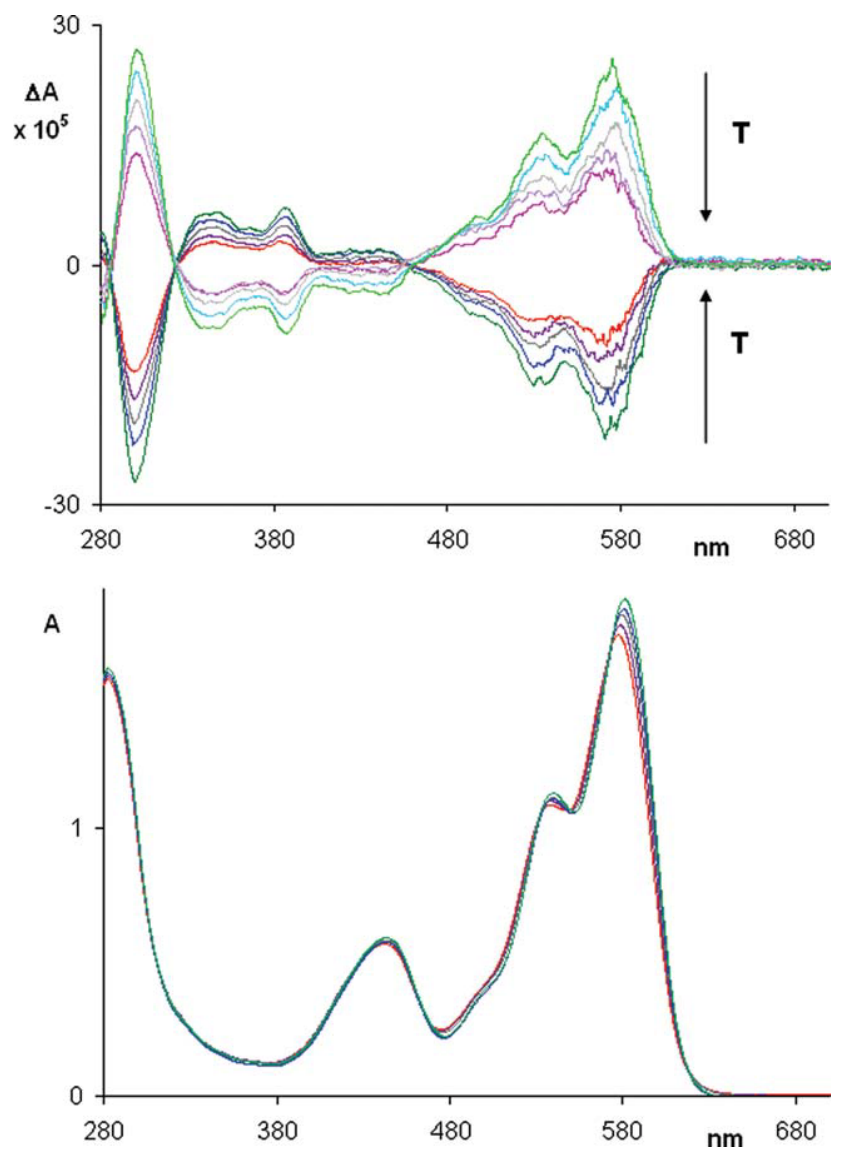

Fig. 4. Top pannel: Experimental ECD spectra of ROT-300 in (-)-diethyl D-tartrate and in (+)-diethyl L-tartrate at $T=293 \mathrm{~K}$ (red and pink curves), $T$ $=283 \mathrm{~K}$ (dark and light purple curves), $T=273 \mathrm{~K}$ (dark and light gray curves), $T=263 \mathrm{~K}$ (dark and light blue curves), and $T=253 \mathrm{~K}$ (dark and ligth green curves). Bottom pannel: Experimental absorption spectra of ROT300 in (-)-diethyl D-tartrate at $T=293 \mathrm{~K}$ (red curve), $T=283 \mathrm{~K}$ (dark purple curve), $T=273 \mathrm{~K}$ (dark gray curve), $T=263 \mathrm{~K}$ (dark blue curve), and $T=$ $253 \mathrm{~K}$ (dark green curve). [Experimental absorption spectra of ROT-300 in $(-)$-diethyl L-tartrate are identicall. Solvent spectra subtracted. Spectra taken in $1 \mathrm{~mm}$ thermostated cell ( 10 scans, concentration $4 \times 10^{-4} \mathrm{M}$ ). [Color figure can be viewed in the online issue, which is available at wileyonlinelibrary. com.]

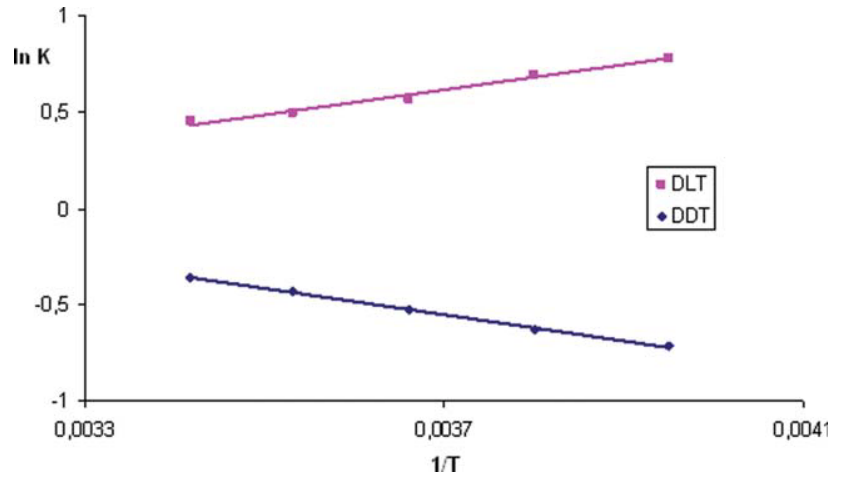

Fig. 5. Natural logarithm of $\mathrm{K}$ equilibrium constant vs. $1 / T$. The experimental values of $K$ are derived from the $\mathrm{CD}$ intensity of the $300 \mathrm{~nm}$ band of Figure 4 and the method employed in Table 2. [Color figure can be viewed in the online issue, which is available at wileyonlinelibrary.com.]

enantiomeric conformer of ROT-300, the other enantiomeric form favors the opposite one. By running variable temperature ECD spectra on one of the systems, we have provided an experimental measure of $\Delta G^{\circ}, \Delta H^{\circ}$, and $\Delta S^{\circ}$. The precise mechanism and forces involved in the solvent/solute interaction and providing the imbalance is unknown, but we point out in Figure 2 that there is a significant red shift of the 585 $\mathrm{nm}$ band for phenyl ethanol solvent, possibly meaning that a $\pi-\pi$ interaction between solvent and solute is important. However we cannot exclude intermolecular hydrogen bonding interactions which are present for three couples of solvent: only for carvone the latter factors are absent.

\section{CONCLUSIONS}

In this work, we have demonstrated that ROT-300 molecule, which is an achiral dye, exhibits an equilibrium between enantiomeric conformers. When this dye is dissolved in chiral solvents, an enantiomeric excess appears and is correlated to the chirality of the solvent. We think that the present investigations migth be relevant also in emission, due to the peculiar luminescence properties spectra of ROT-300. Finally we asked ourselves whether the same phenomenon be observable on other dye-molecules: for this reason we tested the same chiral solvents on Orange-240, i.e., $N, N^{\prime}$-bis (2,6-diisopropylphenyl)-perylene-3,4:9,10-tetracarboxydiimide but we did not find the same nice intense ECD spectra reported in Figure 2 for ROT-300. In that case, the observed UV features are narrower and the ECD ones are not observed at the experimental conditions adopted for ROT-300. Orange-240 differs from ROT-300 in the substitution of the four O-Phenylgroups with hydrogen atoms. By DFT calculations, a completely flat central perylene unit is predicted, which makes us think that the $O$-Phenyl groups of ROT-300 have an important role.

\section{ACKNOWLEDGMENTS}

The authors thank the University of Brescia for supporting Marco Passarello. The Researchers from Brescia also thank CILEA for access to their computational facilities and use of Gaussian09.

\section{LITERATURE CITED}

1. Stephens PJ, Devlin FJ, Cheeseman JR, Frisch MJ, Rosini C. Determination of absolute configuration using optical rotation calculated using density functional theory. Org Lett 2002;4:4595-4598. 
2. Polavarapu PL. Optical rotation: recent advances in determining the absolute configuration. Chirality 2002;14:768-781.

3. Crawford TD. Ab initio calculation of molecular chiroptical properties. Theor Chem Acc 2006;115:227-245.

4. Lightner DA, Gurst JE. Organic conformational analysis. Stereochemistry from circular dichroism spectroscopy. New York: Wiley-VCH; Chapter 4; 2000a. p 63-94.

5. Lightner DA, Gurst JE. Organic conformational analysis. Stereochemistry from circular dichroism spectroscopy. New York: Wiley-VCH; Chapter 5; 2000b. p 95-137.

6. Coulombeau C, Rassat A. Effets de solvant sur le dichroïsme circulaire des cétones rigides dérivées du norcamphre. Bull Soc Chim France 1966;12:3752-3762.

7. Rodger A, Rodger M. Circular dichroism of the carbonyl $n-\pi^{*}$ transition: an independent systems/perturbation approach. J Am Chem Soc 1988;110:2361-2368.

8. Polavarapu PL. Predictions of chiroptical vibrational properties. Int J Quantum Chem 2006;106:1809-1814.

9. Debie E, Jaspers L, Bultinck P, Herrebout W, Van Der Veken B. Induced solvent chirality: a VCD study of camphor in $\mathrm{CDCl}_{3}$. Chem Phys Lett 2008;450:426-430.

10. Filder J, Rodger M, Rodger A. Chiral solvent structure around chiral molecules: experimental and theoretical study. J Am Chem Soc 1994;116:7266-7273.

11. Stagira S, Nisoli M, Cerullo G, Zavelani-Rossi M, De Silvestri S, Lanzani G, Graupner W, Leising G. The role of amplified spontaneous emission in the ultrafast relaxation dynamics of polymer films. Chem Phys Lett 1998;289:205-210.

12. Osswald P, Würthner F. Effects of bay substituents on the racemization barriers of perylene bisimides: resolution of atropo-enantiomers. J Am Chem Soc 2007;129:14319-15326.

13. Frisch MJ, Trucks GW, Schlegel HB, Scuseria GE, Robb MA, Cheeseman JR, Scalmani G, Barone V, Mennucci B, Petersson GA, Nakatsuji H, Caricato M, Li X, Hratchian HP, Izmaylov AF, Bloino J, Zheng G, Sonnenberg JL, Hada M, Ehara M, Toyota K, Fukuda R, Hasegawa J, Ishida M, Nakajima T, Honda Y, Kitao O, Nakai H, Vreven T, Montgomery JA Jr,
Peralta JE, Ogliaro F, Bearpark M, Heyd JJ, Brothers E, Kudin KN, Staroverov VN, Kobayashi R, Normand J, Raghavachari K, Rendell A, Burant JC, Iyengar SS, Tomasi J, Cossi M, Rega N, Millam JM, Klene M, Knox JE, Cross JB, Bakken V, Adamo C, Jaramillo J, Gomperts R, Stratmann RE, Yazyev O, Austin AJ, Cammi R, Pomelli C, Ochterski JW, Martin RL, Morokuma K, Zakrzewski VG, Voth GA, Salvador P, Dannenberg JJ, Dapprich S, Daniels AD, Farkas Ö, Foresman JB, Ortiz JV, Cioslowski J, Fox DJ. Gaussian, Inc.: Wallingford, CT, 2009.

14. Furche F, Ahlrichs R, Wachsmann C, Weber E, Sobanski A, Vögtle F and Grimme S. Circular dichroism of helicenes investigated by time-dependent density functional theory. J Am Chem Soc 2000;122:1717-1724.

15. Cahn RS, Ingold CK, Prelog V. Specification of molecular chirality. Angew Chem Int Ed Eng 1966;5:385-415.

16. Brittain HG. Applications of chiroptical spectroscopy in the characterization of compounds having pharmaceutical importance. In: Berova N, Nakanishi K, Woody RA, editors. Circular dichroism-principles and applications. New York: Wiley-VCH; Chapter 29; 2000. p 819-844.

17. Salvadori P, Di Bari L, Pescitelli G. HPLC-CD: stereochemical analysis at work. In: Berova N, Nakanishi K, Woody RA. Circular dichroism-principles and applications. New York: Wiley-VCH; Chapter 28; 2000. p 797-818.

18. Al-Kaysi RO, Ahn TS, Müller AM, Bardeen CJ. The photophysical properties of chromophores at high (100 mM and above) concentrations in polymers and as neat solids. Phys Chem Chem Phys 2006;8:3453-3459.

19. Würthner F, Chen Z, Dehm V, Stepanenko V. One-dimensional luminescent nanoaggregates of perylene bisimides. Chem Commun 2006;11: 1188-1190.

20. Kaiser TE, Stepanenko V, Würthner F. Fluorescent J-Aggregates of coresubstituted perylene bisimides: studies on structure-property relationship, nucleation-elongation mechanism, and sergeants-and-soldiers principle. J Am Chem Soc 2009;131:6719-6732.

21. Moscowitz A, Wellman K, Djerassi C. Populations and thermodynamic data from temperature dependent circular dichroism measurements. J Am Chem Soc 1963;85:3515-3516.

22. Moscowitz A, Wellman K, Djerassi C. Effect of solvation upon optically active molecules. Proc Natl Acad Sci USA 1963;50:799-804. 